\title{
Erratum to: Effect of Thermocycling on Nickel Release from Orthodontic Arch Wires: An In Vitro Study
}

\author{
Ahmad Sheibaninia ${ }^{1}$
}

Published online: 14 May 2015

(C) Springer Science+Business Media New York 2015

Erratum to: Biol Trace Elem Res (2014) 162:353-359

DOI 10.1007/s12011-014-0136-Z

Due to an oversight, the lab used by Dr. Sheibaninia to analyze his samples was not identified. The lab in question is Behrad Laboratory, Ashrafi Esfahani Blvd., Tehran, Iran. The author and Editors regret the oversight.

The online version of the original article can be found at http://dx.doi.org/ 10.1007/s12011-014-0136-z.

$\triangle \quad$ Ahmad Sheibaninia

asheibaninia@yahoo.com

1 Fellowship of Orthosurgery, Department of Orthodontic, Islamic Azad University, Dental Branch, No.4, 10th Neyestan Alley,

Pasdaran Ave., P. O. Box 19585-175, Tehran, Iran 